\title{
Farinha de entrecasca de melancia em biscoitos sem glúten
}

\author{
Watermelon flour rind in gluten-free cookies
}

\author{
Jacinete Pereira Lima $^{I^{*}}$ Julianne Viana Freire Portela $^{\mathrm{II}}$ Lo-Ruama Marques ${ }^{\mathrm{I}}$ \\ Maristela Alves Alcântara' ${ }^{I}$ Ânoar Abbas El-Aouar ${ }^{I}$
}

\section{RESUMO}

Objetivo foi avaliar a farinha da entrecasca de melancia, desenvolver e estudar a aplicação desta farinha em biscoitos sem glúten (CT), fonte de fibra (F1) e com alto conteúdo de fibra alimentar (F2). A farinha obtida por secagem convectiva $\left(60^{\circ} \mathrm{C}\right.$; velocidade $\left.3 \mathrm{~m} \mathrm{~s} \mathrm{~s}^{-1}, 240 \mathrm{~min}\right)$ e trituração apresentou rendimento de 1,84\%. As formulações de biscoitos com adição de diferentes concentrações de farinha de entrecasca de melancia respeitaram o disposto na $R D C n^{\circ} 54 / 2012$. A matéria in natura, farinha e biscoitos foram analisados quanto aos parâmetros físico-químicos, sendo esses dois últimos analisados ainda quanto aos atributos fisicos. Os biscoitos foram caracterizados quanto à microbiologia e análise sensorial. Os resultados foram avaliados por teste de Tukey com 5\% de significância. A farinha obteve valores significativos de fibra alimentar $(33,3 \%)$ e minerais

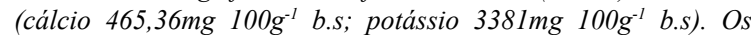
biscoitos apresentaram expressivos teores de cinzas para F1 e F2 com relação à CT. As formulações CT e F1 obtiveram índices de aceitabilidade (>70\%) e melhores respostas quanto aos aspectos de dureza e fraturabilidade. À medida que se acrescentou farinha $d a$ entrecasca intensificou-se o parâmetro $a^{*}$ (mais avermelhado) nos biscoitos. A farinha da entrecasca de melancia pode ser considerada uma alternativa como ingrediente em produtos de panificação para suplementação de fibras e minerais.

Palavras-chave: farinha de arroz, farinha sem glúten, fibra alimentar, biscoitos, análise sensorial.

\section{ABSTRACT}

The study aimed to evaluate the flour produced from the watermelon rind gluten free (CT), to develop and to study the use flour from the watermelon rind to formulations of the cookies source dietary fiber (F1) and with high content of dietary fiber (F2). The flour was obtained by convective drying $\left(60^{\circ} \mathrm{C}\right.$; velocity $3 \mathrm{~m} \mathrm{~s}^{-1}, 240 \mathrm{~min}$ ) and grinding in a yield of $1.84 \%$. The formulations of the cookies with different concentrations of the flour from the watermelon rind considered RDC $n^{\circ}$ 54/2012. Matter in natura, flour and cookies were analyzed through physicochemical parameters, the latter two also analyzed by their physical attributes. Cookies were characterized by their microbiology and sensorial analysis. The results were evaluated by Tukey test with 5\% of significance. The flour obtained significant amounts of dietary fiber (33.3\%) and

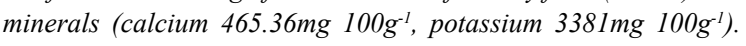
The cookies presented significant amounts of ash into F1 and F2 with respect to $C T$. The formulations $C T$ and F1 obtained indexes acceptability (>70\%) and better responses to the aspects of hardness and brittleness. As it was added flour from the watermelon rind gluten free it was intensified the parameter $a^{*}$ (reddishr) in the cookies. The flour from watermelon rind can be considered alternative as an ingredient in baking goods for supplementation of fibers and mineral.

Key words: rice flour, gluten free flour, dietary fiber, cookies, sensorial analysis.

\section{INTRODUÇÃO}

O Brasil é o quarto maior produtor de frutas, no entanto, há crescente desperdício de cascas de frutas e vegetais com relevantes perdas nutricionais de minerais e fibras alimentares, passando a serem materiais de interesse científico para desenvolvimento de novos produtos (MELO et al., 2006; FAO, 2010). Especificamente, as fibras alimentares atuam como marcador do estado geral de saúde e do cólon humano por meio do aumento do volume e maciez do bolo fecal, aumento da frequência e regularidade de evacuações, além de promover redução do colesterol e/ou glicose sanguíneos (VAN DOKKUM, 2008).

Diante deste fato, tem-se inserido a técnica de obtenção de farinhas a partir de tais resíduos com

'Programa de Pós-graduação e Ciência e Tecnologia de Alimentos, Universidade Federal da Paraíba (UFPB), Campus I, Castelo Branco,
58051-970, João Pessoa, PB, Brasil. E-mail: jacinetelima@hotmail.com. *Autor para correspondência.

IIDepartamento de Nutrição, Centro de Ciências da Saúde (CCS), Universidade Federal do Piauí (UFPI), Picos, PI, Brasil. 
o intuito de utilizá-las na elaboração de produtos de panificação e massas alimentícias, ampliando a oferta de produtos funcionais, inclusive para os celíacos, os quais possuem como único tratamento a exclusão do glúten da dieta (GUIMARÃES et al., 2010). Destacase a categoria biscoito, a qual é aceita e consumida por pessoas de qualquer idade e, por isso, tem-se formulado produtos fontes de diversos nutrientes, aliando-se ao grande apelo por melhor qualidade da dieta (FASOLIN et al., 2007). Dessa forma, o presente trabalho objetivou avaliar a farinha da entrecasca de melancia e estudar sua aplicação na formulação de biscoitos isentos de glúten, fonte e com alto teor de fibra alimentar, por meio dos aspectos nutricional, físico, microbiológico e sensorial.

\section{MATERIAL E MÉTODOS}

No estudo, foram utilizadas melancias (Citrulus lanatus) adquiridas em uma empresa local. A entrecasca da melancia in natura foi caracterizada com relação à atividade de água; acidez total titulável (BRASIL, 2008), pH, umidade; cinzas, minerais (cálcio, ferro e fósforo) por fotometria de chama, proteínas (AOAC, 2000), açúcares totais, redutores e não-redutores (NELSON, 1944) e pectina (CARVALHO et al., 2002). A farinha da entrecasca foi, ainda, caracterizada quanto aos teores de potássio e fibra alimentar (AOAC, 2000).

Os biscoitos foram submetidos às análises supracitadas e à quantificação de lipídeos (FOLCH et al., 1957), excetuando-se a fibra alimentar. Foram, ainda, avaliados quanto ao: volume específico (PIZZINATTO et al., 1993), diâmetro, espessura e índice de expansão (AACC, 1995), cor, dureza e fraturabilidade com texturômetro com o probe em forma de lâmina, utilizando os parâmetros: velocidades: pré-teste $=1,00 \mathrm{~mm} \mathrm{~s}^{-1}$; teste $=3,00 \mathrm{~mm}$ $\mathrm{s}^{-1}$ e pós-teste $=10,00 \mathrm{~mm} \mathrm{~s}^{-1}$; distância: $5,00 \mathrm{~mm}$; e força: 50g (BOURNE, 1978). Para garantir a segurança alimentar dos produtos, foram realizadas determinações de bactérias do grupo coliformes, Staphylocoocus aureus, Bacillus cereus e Salmonelas, de acordo com APHA (2001), seguindo padrões da RDC nำ 12/2001 (BRASIL, 2001).

Obtenção da farinha da entrecasca de melancia

A entrecasca de melancia foi separada da casca e da polpa, utilizando faca inox, sendo, em seguida, cortada em $3 \mathrm{~mm}$ de espessura e, posteriormente, fatiadas e branqueadas $\left(100^{\circ} \mathrm{C}\right.$ $\left.1 \mathrm{~min}^{-1}\right)$; o excesso de água foi retirado com papel absorvente. Após a inativação enzimática, as amostras foram dispostas em espessura de $0,5 \mathrm{~cm}$ em bandejas $(30 \mathrm{~cm} \times 30 \mathrm{~cm})$ e colocadas em secador convectivo de bandejas com circulação forçada de ar, sob condições de processo controladas $\left(60^{\circ} \mathrm{C}\right.$; velocidade $3 \mathrm{~m}$ $\mathrm{s}^{-1}$ e 240 minutos) (PORTELA et al., 2009). Após seca, a amostra foi triturada em multiprocessador de bancada, com rendimento de $1,84 \%$, ou seja, a partir de 5,44kg de entrecasca foram obtidos $100 \mathrm{~g}$ de farinha de entrecasca de melancia.

Elaboração dos biscoitos

A tabela 1 apresenta as formulações de biscoitos sem glúten (CT - sem farinha de entrecasca de melancia, F1 - formulação fonte de fibra alimentar e F2 - formulação com alto conteúdo de fibra alimentar), desenvolvidas com base na formulação convencional com farinha de trigo e adequadas às propriedades tecnológicas da farinha de arroz. A quantidade de farinha de entrecasca de melancia foi definida considerando como alimento fonte de fibra alimentar e com alto conteúdo de fibra alimentar aquele que apresenta, no mínimo, 2,5g e $5,0 \mathrm{~g}$ de fibra por $100 \mathrm{~g}$ de produto, respectivamente (BRASIL, 2012). Os ingredientes secos e líquidos foram misturados, em separado. Em seguida, foram combinados e homogeneizados e moldados em formato arredondado, resultando em porções de $7 \mathrm{~g}$, seguindo para forneamento a $180^{\circ} \mathrm{C}$ por 40 minutos. Após resfriados em dessecador, por 20 minutos, foram acondicionados em embalagens de polipropileno biorientado metalizado à temperatura ambiente.

Tabela 1- Formulação controle (CT); formulação fonte de fibra alimentar (F1); formulação com alto conteúdo de fibra alimentar (F2).

\begin{tabular}{llll}
\hline Ingredientes* & CT $(\mathrm{g})$ & $\mathrm{F} 1(\mathrm{~g})$ & $\mathrm{F} 2(\mathrm{~g})$ \\
\hline Farinha de arroz & 46,06 & 33,80 & 21,20 \\
Farinha da entrecasca de melancia & 0,00 & 9,00 & 18,18 \\
Açúcar mascavo & 4,85 & 4,85 & 4,85 \\
Açúcar demerara & 12,12 & 12,12 & 12,12 \\
Açúcar invertido & 2,42 & 2,42 & 2,42 \\
Gordura de palma & 16,24 & 19,58 & 22,9 \\
Ovo em pó & 2,42 & 2,42 & 2,42 \\
Amido de milho & 5,00 & 5,00 & 5,00 \\
Leite em pó & 3,64 & 3,64 & 3,64 \\
Aroma natural de leite** & 0,30 & 0,30 & 0,30 \\
Bicarbonato de Sódio & 0,30 & 0,30 & 0,30 \\
Bicarbonato de Amônia & 0,30 & 0,30 & 0,30 \\
Pirofosfato de Sódio & 0,30 & 0,30 & 0,30 \\
Água & 6,00 & 6,00 & 6,00 \\
Total & 100,0 & 100,0 & 100,0 \\
\hline
\end{tabular}

*Formulação para $100 \mathrm{~g}$ de biscoito;** Doce Aromas ${ }^{\circledR}$. 
Análise sensorial

O teste de aceitação sensorial aprovado pelo Comitê de Ética em Pesquisa da Universidade Federal da Paraíba (Parecer no 02046712.6.0000.5188), contou com 48 provadores não treinados, os quais assinaram o Termo de Consentimento Livre e Esclarecido. As amostras foram apresentadas em pratos descartáveis brancos codificados com três dígitos aleatórios, monadicamente, em cabine com luz fluorescente. Os provadores avaliaram as amostras quanto aos atributos sabor, cor, textura e aceitação global, utilizando escala hedônica estruturada de nove pontos.

\section{Análise estatística}

Os resultados foram expressos na forma de média e desvio-padrão e submetidos à Análise de Variância (ANOVA) e teste de comparação de médias pelo teste de Tukey, adotando-se 5\% de significância, utilizando o software ASSISTAT, versão 7.6 beta (2002). O Índice de Aceitabilidade (IA) foi calculado a partir da expressão: $\mathrm{IA}(\%)=\mathrm{A} \times 100 / \mathrm{B}$, onde A representa a nota média obtida para o produto, e $\mathrm{B}$ é a nota máxima do produto. Considerou-se aceito produtos com IA \% igual ou superior a $70 \%$ (TEIXEIRA et al., 1987).

\section{RESULTADOS E DISCUSSÃO}

\section{Caracterização da matéria-prima}

A polpa da melancia é marcante por seu alto teor de umidade, sendo tal característica também observada para a entrecasca, conforme apresentado na tabela 2. A entrecasca apresentou quantidades significativas de cálcio $(67,77 \mathrm{mg}$ $\left.100 \mathrm{~g}^{-1}\right)$, ferro $\left(0,51 \mathrm{mg} 100 \mathrm{~g}^{-1}\right)$ e fósforo $(13,30 \mathrm{mg}$ $\left.100 \mathrm{~g}^{-1}\right)$, comparados aos $0,036 \mathrm{mg} 100 \mathrm{~g}^{-1}$ para cálcio, na casca de jambo (AUGUSTA et al., 2010)

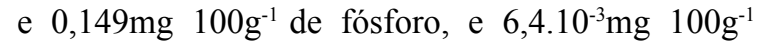
de ferro reportados para casca de $\boldsymbol{C}$. xanthocarpa (VALLILO et al., 2008). Os dados justificam a utilização da entrecasca de melancia também como fonte de minerais importantes à saúde humana.

Caracterização da farinha da entrecasca de melancia

A farinha da entrecasca de melancia apresentou 9,55\% de umidade (Tabela 2), corroborando com o estudo de GUIMARÃES et al. (2010) e com o máximo de $13 \%$ permitido pela legislação brasileira (BRASIL, 2005). O baixo teor de atividade de água $(0,221 \pm 0,01)$ da farinha da entrecasca de melancia é indicativo de inibição do desenvolvimento microbiano. Os valores inversamente proporcionais para acidez total titulável
Tabela 2 - Caracterização da entrecasca de melancia in natura e farinha.

\begin{tabular}{lll}
\hline Análises & $\begin{array}{c}\text { Entrecasca de } \\
\text { melancia } \text { in } \\
\text { natura }\end{array}$ & Farinha \\
\hline Umidade & $96,64 \pm 0,01$ & $9,55 \pm 0,29$ \\
Atividade de água & $0,99 \pm 0,01$ & $0,221 \pm 0,01$ \\
Acidez* & $0,06 \pm 0,01$ & $8,45 \pm 0,58$ \\
pH & $6,16 \pm 0,07$ & $7,14 \pm 0,06$ \\
Proteína & $0,58 \pm 0,05$ & $11,16 \pm 0,40$ \\
Açúcares redutores & $0,48 \pm 0,01$ & $13,45 \pm 0,45$ \\
Açúcares não redutores & $0,34 \pm 0,05$ & $5,14 \pm 0,76$ \\
Açúcares Totais & $0,82 \pm 0,03$ & $18,59 \pm 0,63$ \\
Pectina** & $0,11 \pm 0,03$ & $10,80 \pm 1,36$ \\
Cinzas & $0,83 \pm 0,01$ & $9,97 \pm 0,41$ \\
Cálcio *** & $67,77 \pm 0,16$ & $465,36 \pm 0,44$ \\
Ferro *** & $0,51 \pm 0,02$ & $12,30 \pm 0,08$ \\
Fósforo*** & $13,30 \pm 0,29$ & $178,63 \pm 0,41$ \\
Potássio*** & - & $3781 \pm 0,14$ \\
Fibra alimentar solúvel & - & $5,90 \pm 0,01$ \\
Fibra alimentar insolúvel & - & $27,40 \pm 0,01$ \\
Fibra alimentar total**** & - & $44,1 \pm 0,74$ \\
\hline
\end{tabular}

*expressa em ácido málico. $100 \mathrm{~g}^{-1}$; ** g pectato de cálcio. $100 \mathrm{~g}^{-1}$; $* * * \mathrm{mg} .100 \mathrm{~g}^{-1}$ de matéria seca; **** somatório de fibra solúvel; fibra insolúvel e pectina; todos os demais resultados são expressos em g. $100 \mathrm{~g}^{-1}$.

e $\mathrm{pH}$ demonstram que a matéria-prima apresentava-se em estádio de maturação aceitável para formulação de produtos (PORTELA, no prelo).

O teor de cinzas da farinha $(9,97 \pm 0,41)$ indicou um incremento de mais de dez vezes o obtido para a entrecasca in natura. Estudos revelaram teores de cinzas de 1,7 a 3,8\% para farinha integral de amaranto(KAUR etal., 2010) e 12,72\% para farinha da entrecasca de melancia (GUIMARÃES et al., 2010). Os valores médios de minerais foram expressivos do ponto de vista nutricional, quando comparado ao recomendado pela Dietary Reference Intakes (DRI) para a faixa etária de 9 a 70 anos de ambos os sexos (DRI, 2011). O teor de fósforo, assume de 14,29\% a $25,52 \%$ da DRI; o potássio está compreendido entre 1.950 e $5.900 \mathrm{mg} \mathrm{dia}^{-1}$. Além disso, a farinha pode ser classificada com alto conteúdo de cálcio e ferro, de acordo com a RDC no 54/2012, uma vez que o primeiro corresponde de $46,54 \%$ a $35,80 \%$ da DRI, e o último alcança de 68,33\% a 153,75\% da DRI (DRI, 2011; BRASIL, 2012).

O teor proteico foi significativo $(11,16 \%)$, visto que GUIMARÃES et al. (2010), ao estudarem produto semelhante, reportaram valor dez vezes inferior $(1,20 \%)$, o que pode ser justificado pelas condições de plantio e processamento. É importante 
destacar o potencial quanto ao teor de fibra alimentar total, o qual representa 44,1\% (5,90\% fração solúvel, $27,40 \%$ fração insolúvel e $10,80 \%$ de pectina) da farinha, podendo, desta forma, atuar na prevenção do câncer de colón e doenças cardiovasculares (VAN DOKKUM, 2008; HASSAN et al., 2011). A literatura apresenta $31,01 \%$ para farinha da entrecasca de melancia (GUIMARÃES et al., 2010) e 38,80\% para a casca de Bambangan (Mangifera pajang K.) (HASSAN et al., 2011). Frente aos resultados, podese afirmar que a farinha da entrecasca de melancia é uma relevante alternativa alimentar, em especial como ingrediente de produtos de panificação, pois alcançam uma diversidade de público consumidor.

Caracterização dos biscoitos

$\mathrm{Na}$ tabela 3, observa-se o potencial nutricional dos biscoitos formulados em decorrência da adição de farinha da entrecasca de melancia, por promover incremento estatisticamente diferente entre as formulações, para cinzas e fibra alimentar. Não foram observadas diferenças significativas
$(\mathrm{P} \leq 0,05)$ no que se refere à umidade e atividade de água. Observa-se diferença significativa $(\mathrm{P} \leq 0,05)$ para açúcares e gordura, em função da formulação estabelecida para cada biscoito.

Durante o forneamento, a massa do biscoito modifica-se com relação às dimensões, intensificação da cor e textura (CRONIN; PREIS, 2000). Na tabela 3, observam-se, ainda, variações nos parâmetros físicos dos biscoitos das formulações CT, F1 e F2. Quanto maior foi a adição de farinha de entrecasca de melancia, estatisticamente maiores foram os valores para o parâmetro a*, intensificando a cor avermelhada. Sugere-se, portanto, que as reações de escurecimento não-enzimático sejam mais intensas nas formulações com a referida farinha. Esse fato assemelha-se ao obtido por MOURA et al. (2010) e ZUCCO et al. (2011).

Segundo ASSIS et al. (2009), a dureza é um dos fatores que determina a aceitabilidade do alimento pelo consumidor e, assim como a fraturabilidade, é desejável que seus valores sejam baixos. Constatouse diferença significativamente estatística $(\mathrm{P} \leq 0,05)$

Tabela 3 - Caracterização físico-química e física dos biscoitos CT, F1 e F2.

\begin{tabular}{|c|c|c|c|c|}
\hline \multicolumn{2}{|l|}{ Análises } & \multirow[b]{2}{*}{ CT $(\%)$} & -- Formulações ---- & \multirow[b]{2}{*}{ F2 (\%) } \\
\hline & & & F1 (\%) & \\
\hline \multicolumn{2}{|l|}{ Umidade } & $3,9 \pm 0,227^{\mathrm{a}}$ & $4,8 \pm 0,23^{\mathrm{a}}$ & $4,1 \pm 0,08^{\mathrm{a}}$ \\
\hline \multicolumn{2}{|c|}{ Atividade de água } & $0,334 \pm 0,02^{\mathrm{a}}$ & $0,306 \pm 0,02^{\mathrm{a}}$ & $0,284 \pm 0,03^{\mathrm{a}}$ \\
\hline \multicolumn{2}{|l|}{ Cinzas } & $2,9 \pm 0,17^{\mathrm{a}}$ & $3,7 \pm 0,19^{b}$ & $4,6 \pm 0,19^{c}$ \\
\hline \multicolumn{2}{|l|}{ Proteína } & $5,2 \pm 0,16^{\mathrm{a}}$ & $4,1 \pm 0,17^{\mathrm{b}}$ & $4,0 \pm 0,15^{\mathrm{b}}$ \\
\hline \multicolumn{2}{|c|}{ Açúcares redutores } & $2,4 \pm 0,01^{\mathrm{b}}$ & $4,0 \pm 0,02^{\mathrm{a}}$ & $3,9 \pm 0,01^{\mathrm{a}}$ \\
\hline \multicolumn{2}{|c|}{ Açúcares não redutores } & $12,1 \pm 0,19^{\mathrm{a}}$ & $13,3 \pm 0,44^{\mathrm{b}}$ & $11,1 \pm 0,27^{\mathrm{c}}$ \\
\hline \multicolumn{2}{|c|}{ Açúcares totais } & $14,5 \pm 0,12^{\mathrm{a}}$ & $17,4 \pm 0,46^{\mathrm{b}}$ & $15,0 \pm 0,26^{\mathrm{c}}$ \\
\hline \multicolumn{2}{|c|}{ Gordura } & $16,3 \pm 0,07^{\mathrm{b}}$ & $17,9 \pm 0,45^{\mathrm{a}}$ & $18,0 \pm 007^{\mathrm{a}}$ \\
\hline \multirow{2}{*}{\multicolumn{2}{|c|}{ Análises }} & ----------------. & $\begin{array}{l}\text { Parâmetros físicos -- } \\
\text { - Formulações ----- }\end{array}$ & 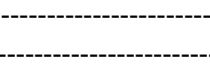 \\
\hline & & CT $(\%)$ & F1 (\%) & F2 (\%) \\
\hline \multirow{3}{*}{ Cor } & $\mathrm{L}^{*}$ & $54,65 \pm 1,77^{\mathrm{a}}$ & $52,38 \pm 1,61^{\mathrm{a}}$ & $42,53 \pm 2,87^{\mathrm{b}}$ \\
\hline & $a^{*}$ & $7,08 \pm 1,61^{\mathrm{a}}$ & $8,83 \pm 0,28^{b}$ & $11,21 \pm 0,41^{\mathrm{c}}$ \\
\hline & $b^{*}$ & $25,93 \pm 0,38^{\mathrm{a}}$ & $28,63 \pm 2,26^{\mathrm{a}}$ & $26,88 \pm 2,44^{\mathrm{a}}$ \\
\hline \multirow{2}{*}{ Textura } & Dureza (g.s) & $2714,28 \pm 359,70^{\mathrm{a}}$ & $1824,34 \pm 433,55^{b}$ & $4592,62 \pm 241,40^{\mathrm{c}}$ \\
\hline & Fraturabilidade (mm) & $0,46 \pm 0,19^{b}$ & $1,34 \pm 0,29^{\mathrm{a}}$ & $0,55 \pm 0,25^{\mathrm{b}}$ \\
\hline \multicolumn{2}{|c|}{ Volume específico (v/m) } & $1,58 \pm 0,08^{\mathrm{a}}$ & $1,62 \pm 0,17^{\mathrm{a}}$ & $1,50 \pm 0,07^{\mathrm{a}}$ \\
\hline \multicolumn{2}{|c|}{ Espessura (mm) } & $9,20 \pm 0,11^{\mathrm{b}}$ & $10,83 \pm 0,16^{\mathrm{a}}$ & $8,68 \pm 0,74^{\mathrm{b}}$ \\
\hline \multicolumn{2}{|c|}{ Diâmetro (mm) } & $39,38 \pm 1,04^{\mathrm{a}}$ & $36,26 \pm 1,60^{\mathrm{a}}$ & $38,3 \pm 1,81^{\mathrm{a}}$ \\
\hline \multicolumn{2}{|c|}{ Índice de expansão } & $51,51 \pm 7,50^{\mathrm{a}}$ & $50,63 \pm 9,82^{\text {a }}$ & $47,45 \pm 2,19^{\mathrm{a}}$ \\
\hline
\end{tabular}

Médias seguidas de letras iguais na mesma linha não diferem significativamente entre si, pelo teste de Tukey, com nível de 5\% de significância; $\mathrm{CT}$ = formulação controle; $\mathrm{F} 1=$ Formulação fonte de fibra alimentar; F2= Formulação com alto conteúdo de fibra alimentar. 
entre as três amostras para o parâmetro dureza. A formulação $\mathrm{F} 2$ apresentou maior valor em relação às CT e F1, possivelmente, devido à alta concentração de fibra proporcionar um maior grau de agregação dos ingredientes no produto final. Somado a isso, a farinha da entrecasca de melancia possui característica própria de maior dureza em relação à farinha de arroz, quando adicionada aos ingredientes do biscoito e acrescida de umidade. Esse fator concorda com o IA\% abaixo de $70 \%$ para o atributo textura (F1 e F2); diferindo do encontrado para biscoitos a base de farinhas de aveia e de arroz parboilizado (ASSIS et al., 2009). Para F2, observou-se maior força de ruptura e menor fraturabilidade, demonstrando que as farinhas de arroz e farinha da entrecasca de melancia apresentam comportamento diferente da farinha de trigo, uma vez que SAHA et al. (2011) observaram menor força de ruptura e maior fraturabilidade. $\mathrm{O}$ volume específico, diâmetro e índice de expansão não apresentaram diferença significativamente estatística $(\mathrm{P} \leq 0,05)$ entre CT, F1 e F2, assemelhandose aos resultados de biscoito de farinhas de aveia e de arroz parbolizado (ASSIS et al., 2009). De acordo com MOURA et al. (2010), o volume específico dos biscoitos é afetado por vários fatores, como a qualidade dos ingredientes utilizados na formulação da massa, especialmente a farinha e as condições de tratamento usadas durante o processamento. As três amostras são estatisticamente diferentes em relação à espessura $(\mathrm{P} \leq 0,05)$. Sendo que F2 apresentou menor valor em função da maior quantidade de fibra alimentar presente no biscoito, diminuindo, dessa forma, o fator expansão (PEREZ et al., 2007; ASSIS et al., 2009; MOURA et al., 2010). Os biscoitos encontram-se adequados quantos aos padrões microbiológicos (BRASIL, 2001), indicando segurança higiênico-sanitária e, permitindo seu uso na alimentação humana.

\section{Análise sensorial}

A formulação CT apresentou aceitação para todos os atributos avaliados, enquanto que a F1 apresentou baixo índice para o atributo sabor e a F2 foi caracterizada como aceita somente com relação à cor (TEIXEIRA et al., 1987). A aceitação decaiu em virtude do incremento de farinha de entrecasca de melancia à formulação de biscoito, sendo que o sabor foi o atributo que apresentou maiores interferências negativas quanto ao índice de aceitação (Figura 1). Essa resposta pode ser em função do gosto meio amargo característico desta farinha. O seu acréscimo também promoveu redução nas respostas para o atributo textura, enquanto que todas as formulações apresentaram índices aceitáveis para a cor.

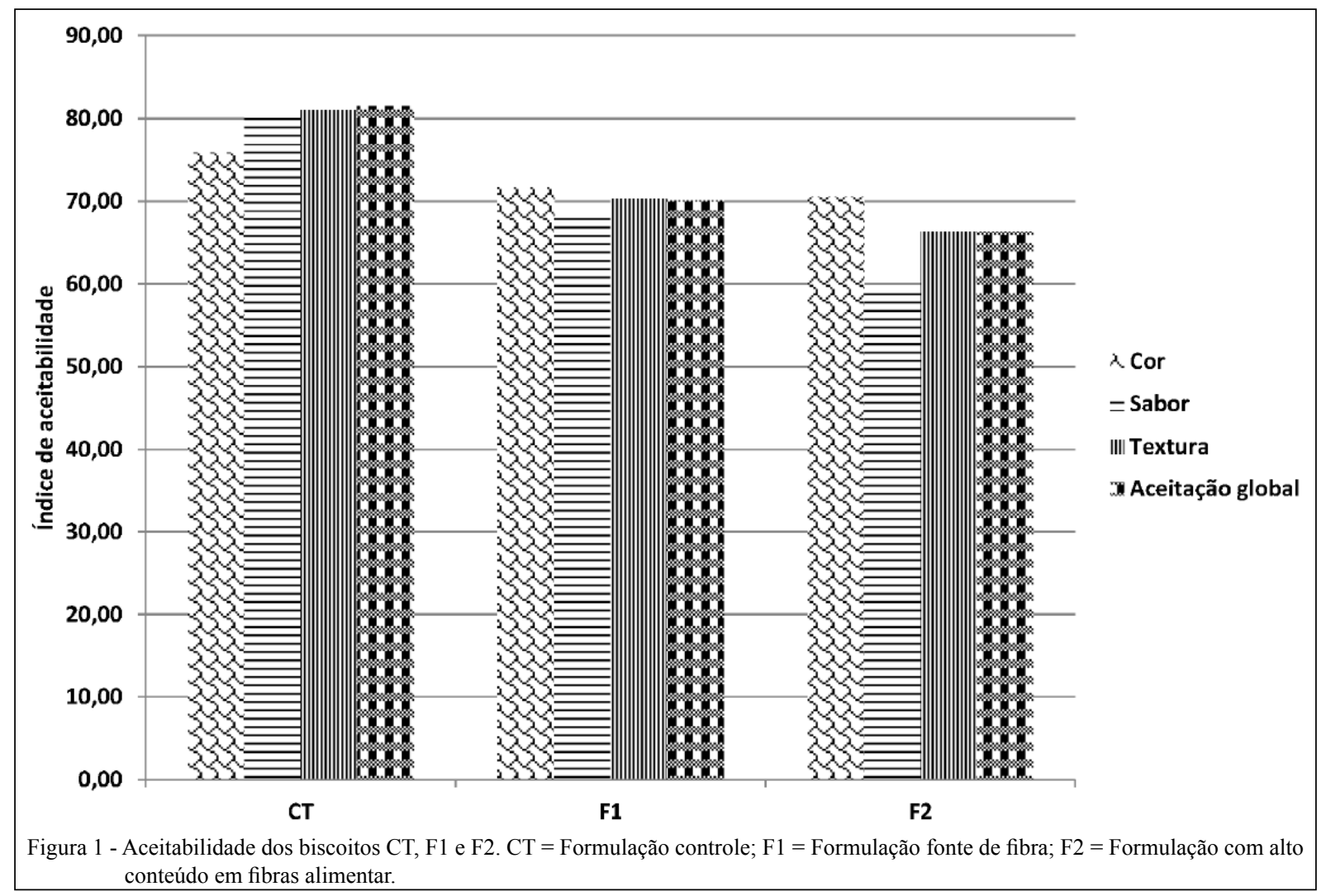

Ciência Rural, v.45, n.9, set, 2015. 


\section{CONCLUSÃO}

A farinha da entrecasca de melancia apresenta expressivas quantidades de minerais e fibra alimentar, surgindo como alternativa para a indústria de panificação, especialmente com a finalidade de ampliar oferta de alimentos isentos de glúten e com aspectos funcionais. A formulação fonte de fibra (F1) destaca-se devidoàs respostas sensoriais e nutricionais.

Aspectos relacionados ao sabor amargo da farinha pode ser objeto de estudos futuros, utilizandose outros pré-tratamentos no material in natura, bem como o uso de aditivos e ou outros ingredientes como formadeotimizaras respostas sensoriais sabor etextura.

\section{AGRADECIMENTOS}

Ao Conselho Nacional de Desenvolvimento Científico e Tecnológico (CNPq).

\section{REFERÊNCIAS}

APHA (AMERICAN PUBLIC HEALTH ASSOCIATION) Compendium of methods for the microbiological examination of foods. 4.ed. Washington, 2001. $676 \mathrm{p}$.

ASSISTAT 7.6 BETA - Assistência estatística. Campina Grande: DEAG, CTRN, Universidade Federal de Campina Grande, PB, 2002. 45 p.

AACC (AMERICAN ASSOCIATION OF CEREAL CHEMISTS). Approved methods of the american association of cereal chemists. 9.ed. St. Paul. 1, 2, 1995. 1200 p.

AOAC (ASSOCIATION OF OFFICIAL ANALYTICAL CHEMISTS). Official methods of analysis. St Paul, 2000. v.2.

ASSIS, L.M. et al. Propriedades nutricionais, tecnológicas e sensoriais de biscoitos com substituição de farinha de trigo por farinha de aveia ou farinha de arroz parboilizado. Alimentos e Nutrição, v. 20, n. 1, p. 15-24, 2009. Disponível em: <http:// serv-bib.fcfar.unesp.br/seer/index.php/alimentos/issue/view/178>. Acesso em: 04 jan. 2013.

AUGUSTA, I.M. et al. Caracterização física e química da casca e polpa de jambo vermelho (Syzygium malaccensis, (L.) Merryl \& Perry). Ciência e Tecnologia de Alimentos, v.4 p.928-932, 2010. Disponível em: <http://www.scielo.br/pdf/cta/v30n4/v30n4a14. pdf $>$. Acesso em: 20 nov. 2012

BRASIL, Instituto Adolfo Lutz. Normas analíticas: métodos químicos e físicos para análises de alimentos. São Paulo, V.2, p.533, 2008

BRASIL, Ministério da Saúde. Agência de Vigilância Sanitária. Regulamento Técnico para produtos de cereais, amidos, farinhas e farelos. Resolução n. 263 de 22 de setembro de 2005. Diário Oficial [da República Federativa do Brasil], Brasília, set. 2005. Seção 1, p.3.

BRASIL. Agência Nacional de Vigilância Sanitária. Resolução RDC n. 12, de 02 de janeiro de 2001: Aprova o regulamento técnico sobre os padrões microbiológicos para alimentos. 2001 Diário Oficial [da República Federativa do Brasil], Brasília, jan. 2001. Seção 1, p.2.
BRASIL. Agência Nacional de Vigilância Sanitária. Resolução RDC n. 54, de 12 de novembro de 2012. Dispõe sobre o Regulamento Técnico sobre Informação Nutricional Complementar. 2012. Diário Oficial [da República Federativa do Brasil], Brasília, nov. 2012. Seção 1, p.3.

BOURNE, M.C. Texture profi le analysis. Food Technology, v.7, n.32, p.62-66, 1978.

CARVALHO, H.H. et al. Alimentos: métodos físicos e químicos de análises. Porto Alegre: Universidade Federal do Rio Grande do Sul, 2002, 180 p.

CRONIN, K.; PREIS, C. A statistical analysis of biscuit physical properties as affected by baking. Journal of Food Engineering, v.46, p.217-225, 2000

DRI (DIETARY REFERENCE INTAKES). Estimated average requirements. Beltsville. Food and Nutrition Board, Institute of Medicine, National Academies, 2011. 8 p

FAO (FOOD AND AGRICULTURE ORGANIZATION OF THE UNITED NATIONS). FAOSTAT, 2010. Disponível em: $<$ http://faostat. fao.org/site/339/default.aspx.dados2010.>. Acesso em: 18 abr. 2012.

FASOLIN, L.H. et al. Biscoitos produzidos com farinha de banana: Avaliações química, física e sensorial. Ciência e Tecnologia de Alimentos, v.27, n.3, p.524-529, 2007.

FOLCH, J. et al. A simples method for the isolation and purification of total lipids from animal tissues. Journal Biological Chemistry, v.226, p.497-509, 1957.

GUIMARÃES, R.R. et al. Bolos simples elaborados com farinha da entrecasca de melancia (Citrullus vulgaris, sobral): avaliação química, física e sensorial. Ciência e Tecnologia de Alimentos, v.2, p.354-363, 2010.

HASSAN, F.A. et al. Characterisation of fibre-rich powder and antioxidant capacity of Mangifera pajang K. fruit peels. Food Chemistry, v.126, p.283-288, 2011.

KAUR, S. et al. Amaranthus hypochondriacus and Amaranthus caudatus germplasm: Characteristics of plants, grain and flours. Food Chemistry, v.123, p.1227-1234, 2010.

MELO, E.A. et al. Capacidade antioxidante de hortaliças usualmente consumidas. Ciência e Tecnologia de Alimentos, v.26, n.3, p.639-644, 2006.

MOURA, F.A. et al. Biscoitos tipo cookie elaborados com diferentes frações de semente de abóbora (Curcubita maxima). Alimentos e Nutrição. Araraquara, v. 21, n. 4, p. 579-585, 2010.

NELSON, N.A. A photometric adaptation of Somogyi method for determination of glicose. Journal Biological Chemistry, v.135, p.375, 1944.

PIZZINATTO, A. et al. Avaliação tecnológica de produtos derivados de farinhas de trigo (pão, macarrão, biscoito). ITAL, v.30, p.54, 1993.

PEREZ, P.M.P. et al. Elaboração de biscoitos tipo salgado, com alto teor de fibra alimentar, utilizando farinha de berinjela (Solanum melongena, L.). Ciência e Tecnologia de Alimentos, v.27, p.186-192, 2007.

Ciência Rural, v.45, n.9, set, 2015. 
PORTELA, J. V. F. et al . Evaluación de la Transferencia de Masa Durante el Secado de la Corteza de la Sandía para la Obtención y Caracterización de la Harina. Revista de Ciencia y Tecnología (no prelo).

PORTELA, J. V. F. Estudo dos aspectos tecnológicos e de qualidade envolvidos no aproveitamento da casca e da polpa da melancia (Citrullus lanatus Schrad). 2009, 132 f. Dissertação (Mestrado em Ciência e Tecnologia de Alimentos) - Centro de Tecnologia, Universidade Federal da Paraíba, João Pessoa, 2009.

SAHA, S. et al. Compositional and varietal influence of finger millet flour on rheological properties of dough and quality of biscuit. Food Science and Technology, v.44, p.616-621, 2011.

TEIXEIRA, E. et al. Métodos sensoriais. In: UFSC. Análise sensorial de alimentos. Florianópolis: UFSC, 1987. p.66-119.
VALliLO, M.I. et al. Composição química dos frutos de Campomanesia xanthocarpa Berg-Myrtaceae. Ciência e Tecnologia de Alimentos, v.28 p.231-237, 2008. Disponível em: $\quad<$ http://www.scielo.br/scielo.php?script=sci_arttext\&pid $=$ S0101-20612008000500035>. Acesso em: 5 jan. 2013 .

VAN DOKKUM, W. Propriedades funcionais de fibras alimentares, amido resistente e oligossacarídeos não digeríveis. In: COSTA, N.M.B.; ROSA, C.O.B. (Ed). Alimentos funcionais: benefícios para a saúde. Viçosa, Editora: Rubio, 2008. p. 20.

ZUCCO, F. et al. Physical and nutritional evaluation of wheat cookies supplemented with pulse flours of different particle sizes. Food Science and Technology, v.44, p.2070 e 2076, 2011. 